\title{
SVN53-67/M57-KLH Peptide Vaccine
}

National Cancer Institute

\section{Source}

National Cancer Institute. SVN53-67/M57-KLH Peptide Vaccine. NCI Thesaurus. Code C95705.

A peptide vaccine containing a 15-mer peptide (DLAQMFFCFKELEGW), with C to $\mathrm{M}$ alteration at amino acid position 57, derived from the anti-apoptosis protein survivin, and conjug ated with keyhole limpet hemocyanin (KLH), with potential immunopotentiating and antineoplastic activities. Upon subcutaneous administration of SVN53-67/M57-KLH peptide vaccine, this peptide is able to bind both HMC class I and II molecules and may activate the immune system to mount a cytotoxic T-lymphocyte (CTL) as well as a Thelper cell response ag ainst survivin-expressing cancer cells. This may result in decreased tumor cell proliferation and ultimately tumor cell death. Survivin, a member of the inhibitor of apoptosis (IAP) family, expressed during embryonic development while absent in most normal adult cells, is upregulated in a variety of human cancers; its expression in tumors is associated with a more aggressive phenotype, decreased survival, and increased resistance to chemotherapy. KLH may enhance immune recognition and may promote an enhanced response. As SVN53-67 is weakly immunogenic in humans, the M57 alteration may lead to greater affinity towards HLA-A*0201 and thus an enhanced antitumor immune response. 